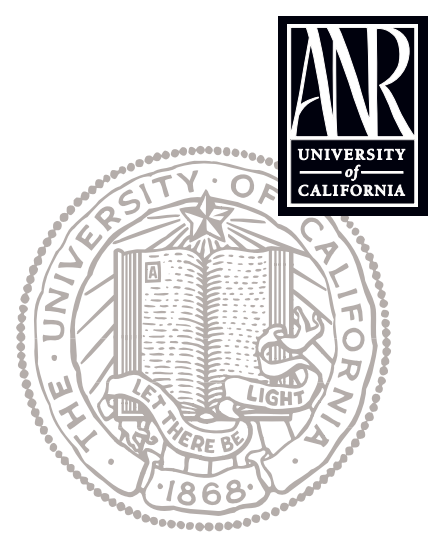

UNIVERSITY OF CALIFORNIA

Division of Agriculture and Natural Resources http://anrcatalog.ucdavis.edu

\title{
Vine Mealybug: What You Should Know
}

KRIS GODFREY, California Department of Food and Agriculture; DAVID HAVILAND, University of California Cooperative Extension, Kern County; JEFFREY ERWIN, Napa County Agricultural Commissioner's Office; KENT DAANE, University of California, Berkeley; WALT BENTLEY, University of California Cooperative Extension, Kearney Agricultural Center

The vine mealybug (VMB) is an economic pest of vineyards in the Mediterranean regions of Europe, Africa, and the Middle East, as well as in South Africa, Pakistan, and Argentina. It is currently localized in all grape-growing regions of California. This small, cryptic insect infests all parts of the vine and produces large amounts of honeydew (clear, sugary excretions) that damage the fruit and foliage, resulting in unmarketable grapes (fig. 1). The insect also causes the vine to decline in vigor and production and transmits leafroll viruses. Costs associated with management programs for this pest have caused California grape growers to identify VMB as a pest of serious economic significance.

\section{VINE MEALYBUG BIOLOGY}

VMBs are very small (adult females are about $1 / 8$ inch $[3 \mathrm{~mm}]$ in length) and are difficult to see because of their cryptic nature. Female VMBs are oval, flat, and covered with a white, mealy wax. Unlike the females, males are much smaller and have wings (fig. 2).

All VMB life stages are found throughout the vine all year long (fig. 3). There are about 3 to 7 generations per year. In the winter, VMBs primarily are found under the bark and in crevices on the lower trunk and occasionally on roots in light- to medium-textured soils (fig. 4). As temperatures warm, VMB density increases, and the mealybugs move out onto the aerial portions of a vine (fig. 5). VMBs can be
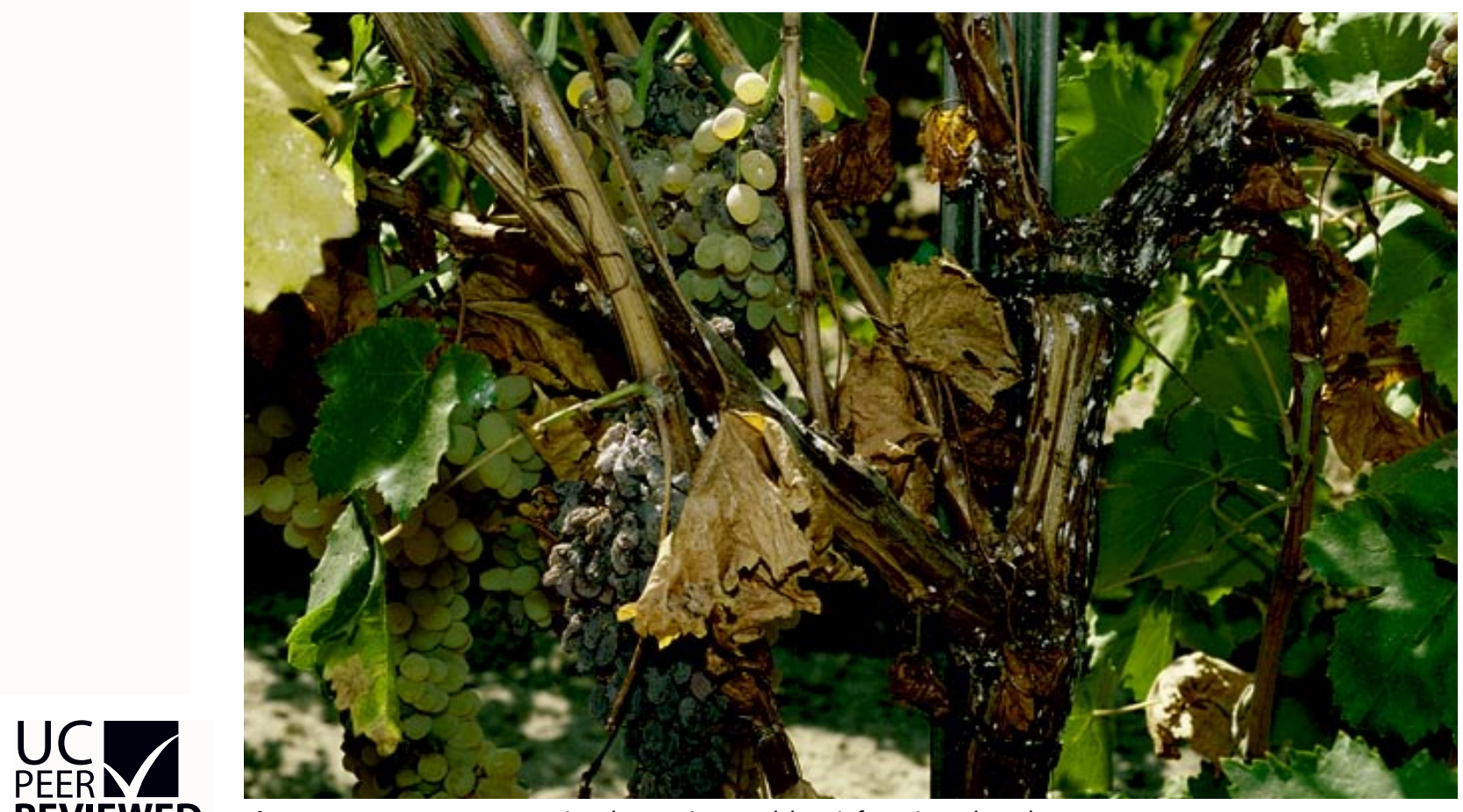

Figure 1. Damage to a grapevine due to vine mealybug infestation. Photo by Kent Daane. 


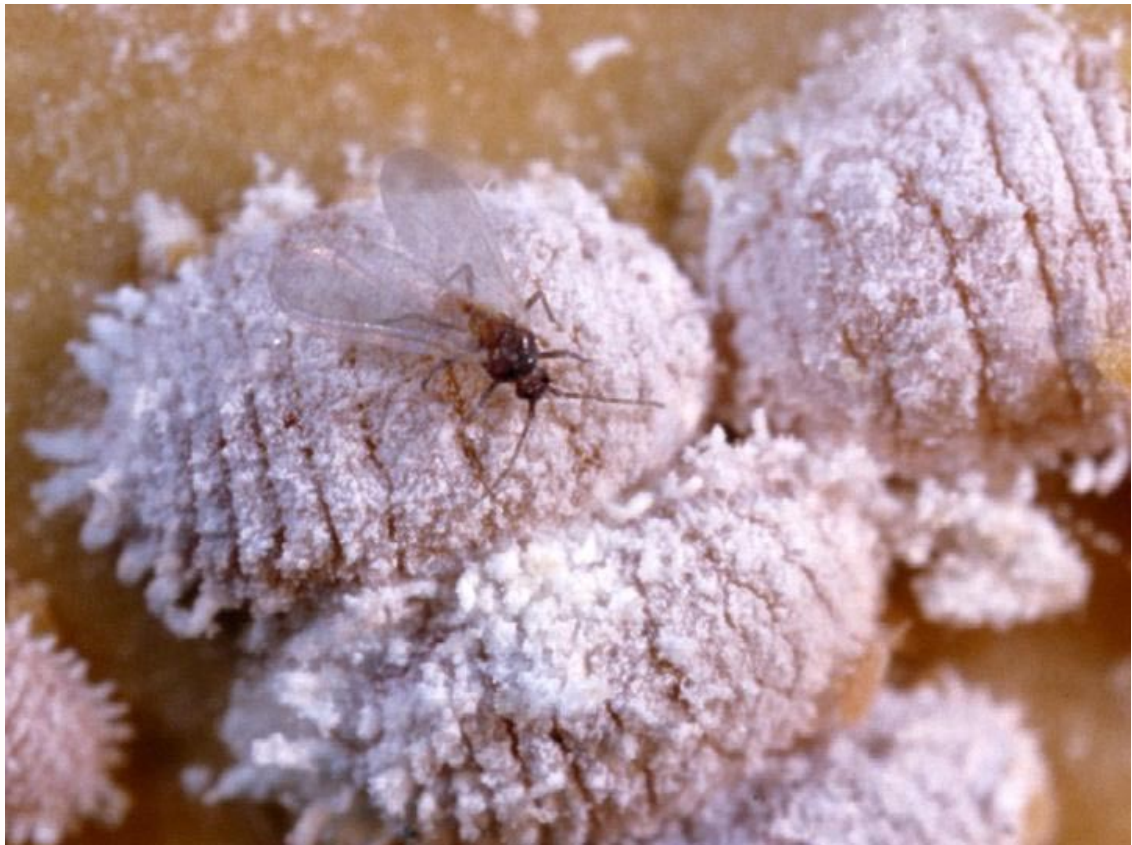

Figure 2. Only VMB males have wings. The males will fly short distances to find a female with which to mate. Photo by Kent Daane.
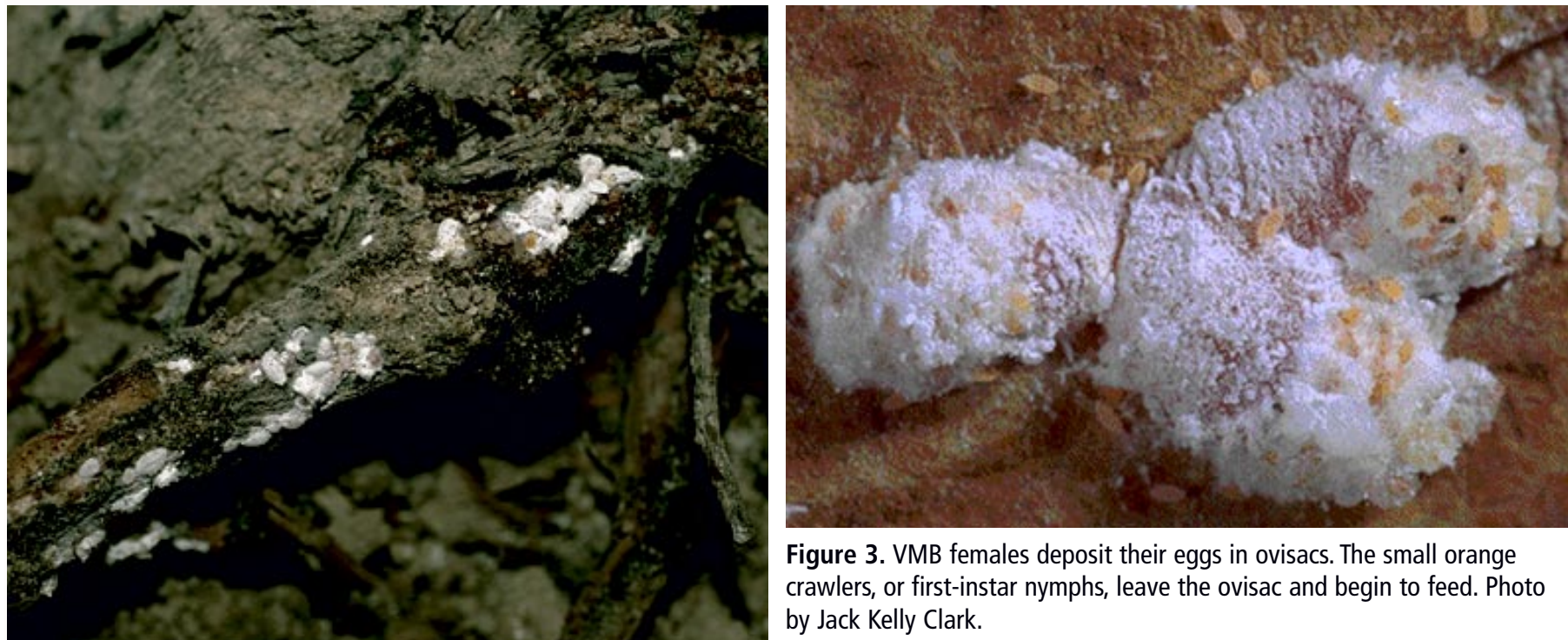

Figure 3. VMB females deposit their eggs in ovisacs. The small orange crawlers, or first-instar nymphs, leave the ovisac and begin to feed. Photo by Jack Kelly Clark.

Figure 4. VMBs may be found on the roots in light- to medium-textured soils. Photo by Kent Daane.

Figure 5. VMBs can be found at the base of a cane. Photo by Kent Daane.

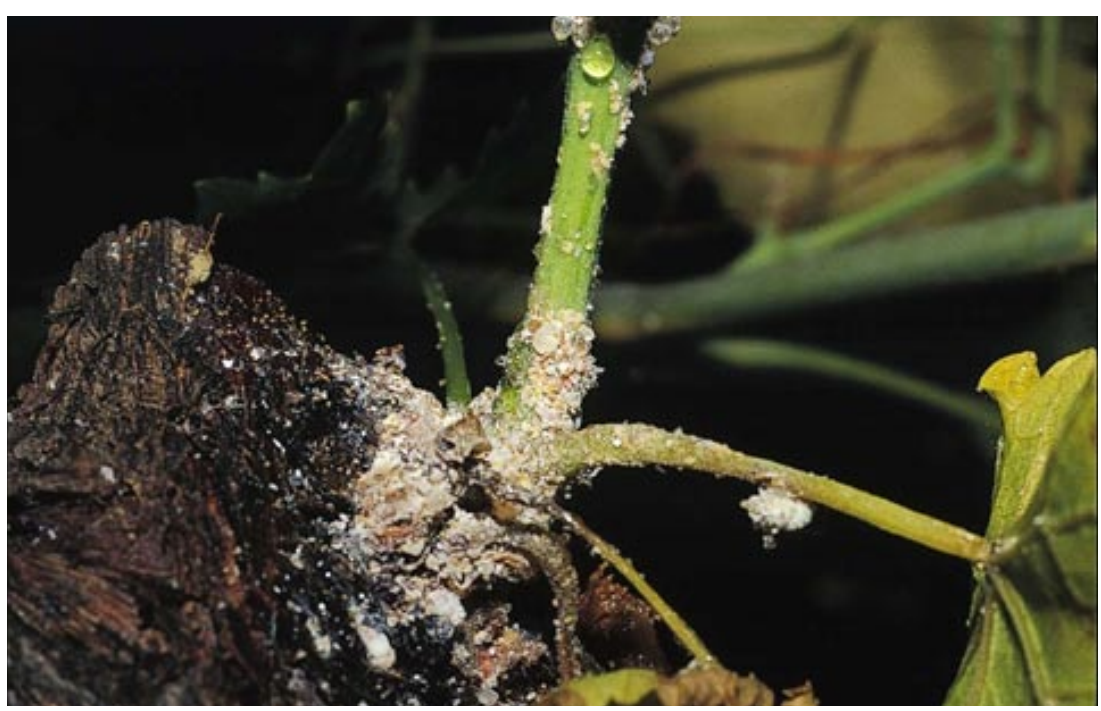


found on the leaves and clusters in late spring through the fall (fig. 6). Shortly after harvest, VMB density declines. This generalized biology fits most VMB populations, but it may vary with location and cultivar.

\section{FINDING VINE MEALYBUGS}

VMBs can be detected either through visual surveys of grapevines or by pheromone trapping. In many cases, stripping bark from the trunk can aid in finding VMB populations. With visual surveys, look for

- intense ant activity on vines, wires, or drip tubing

- black sooty mold or honeydew on the trunk, cordons, leaves, and fruit (fig. 7)

- white waxy substance (clusters of VMBs or VMB egg masses) in crevices in and under bark and on nodes (figs. 8 and 9)

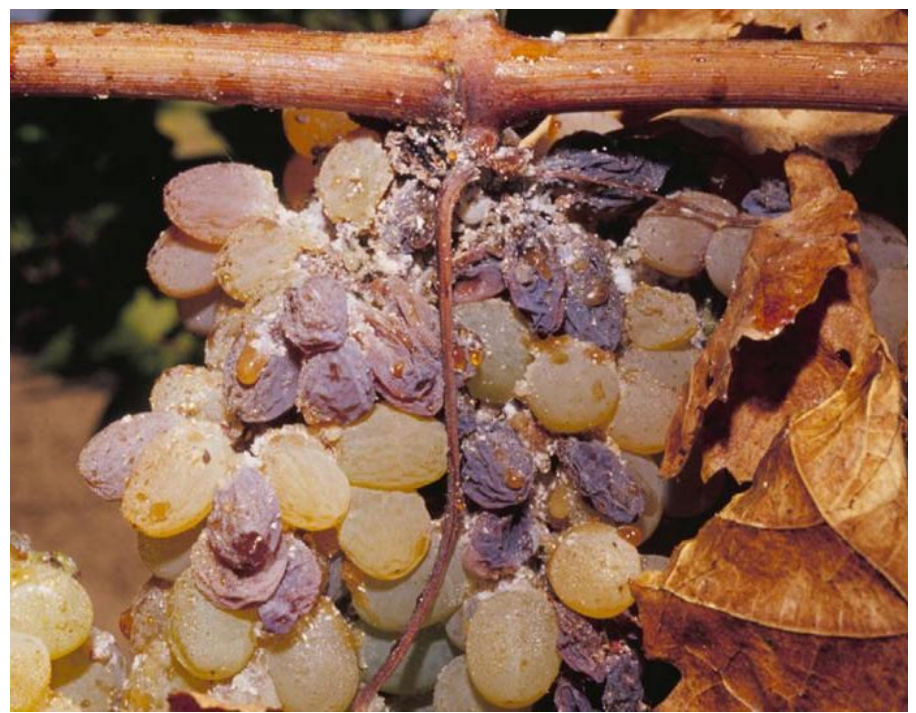

Figure 6. VMBs will also infest clusters. Photo by Kent Daane.

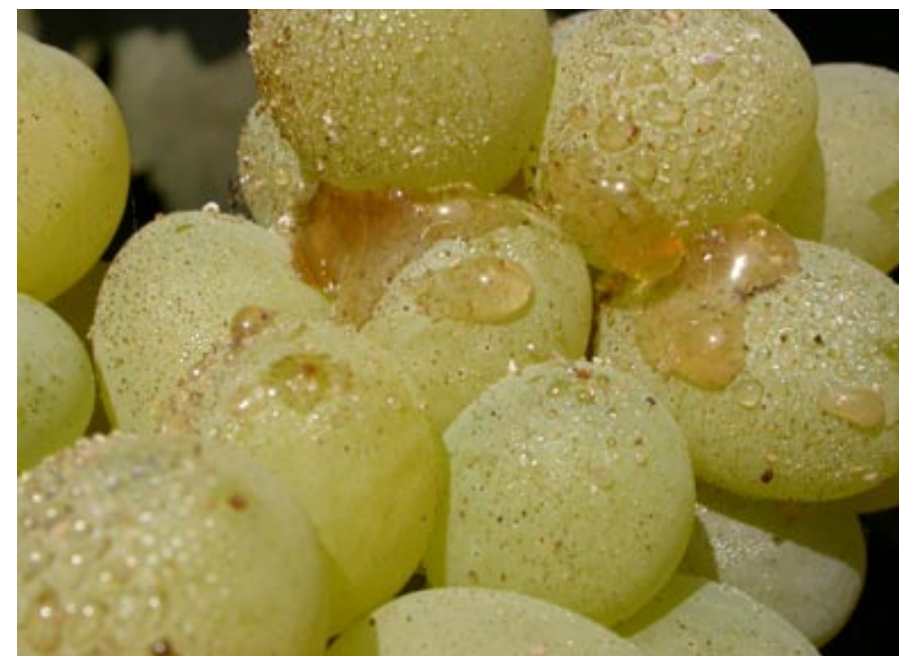

Figure 7. The honeydew produced when VMBs feed inside or above a cluster will cover the berries. Sooty mold grows easily on the sugary honeydew. Photo by David Haviland.

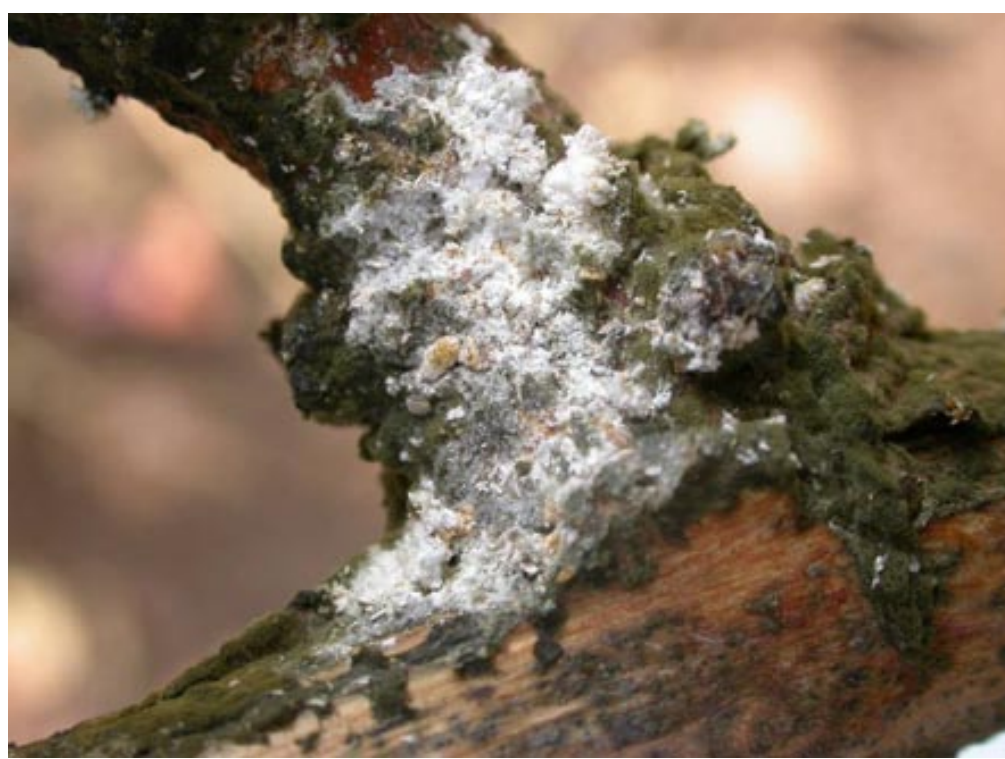

Figure 8. VMBs can be found on the woody parts of the grapevine, including the trunk and cordon. Photo by David Haviland.

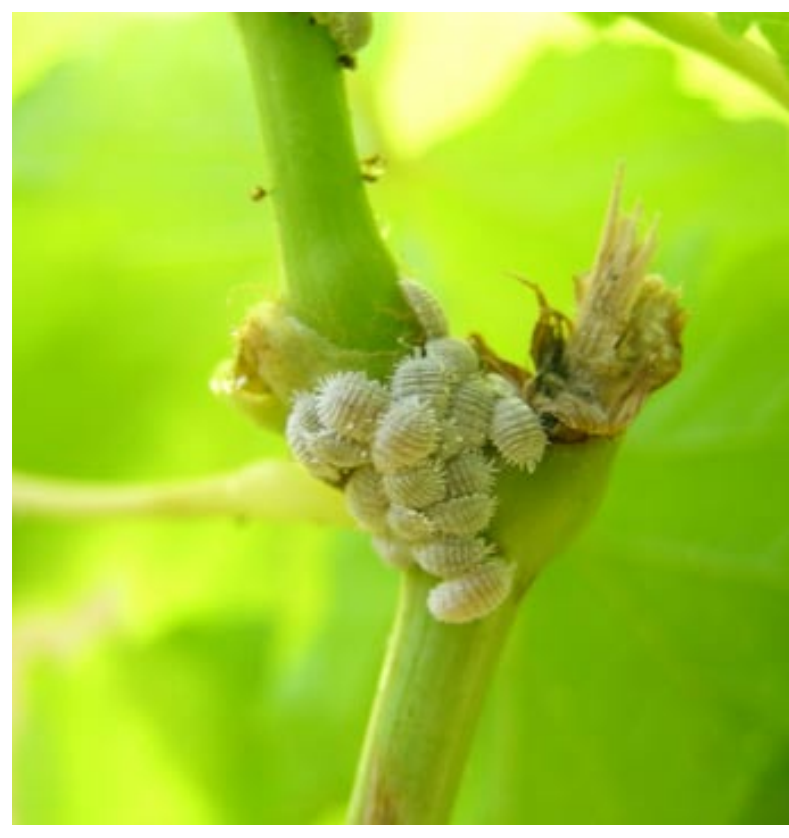

Figure 9. VMBs clustering on a node of a cane. Photo by Vaughn Walton. 


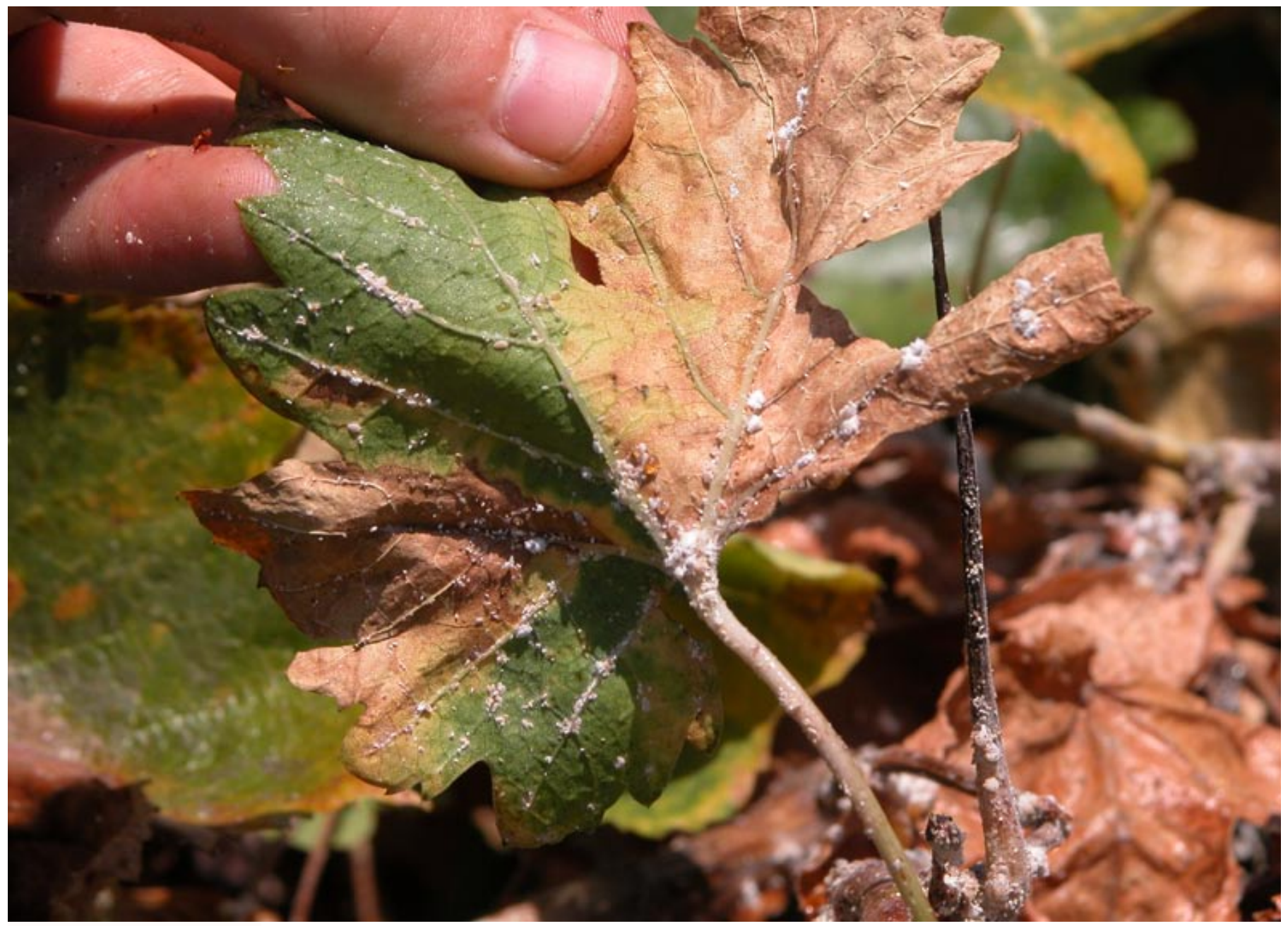

Figure 10. VMBs feeding on grape leaves and causing the leaves to turn brown and abscise. Photo by Kent Daane.

- wet-looking areas on the bark caused by mealybug honeydew

- abscised brown leaves under the vine covered with honeydew and sooty mold (fig. 10)

Pheromone traps can be placed in the vine canopy from bud break through November (fig. 11). There should be at least one trap per 10 to 20 acres ( 4 to 8 ha) of vineyard. These traps will attract VMB males from as far away as 300 feet (about $90 \mathrm{~m}$ ) or more. Your county agricultural commissioner, UCCE Farm Advisor, or pest control adviser (PCA) has guidelines for trap placement and servicing. If more than 10 males are found in a trap in a month, additional traps should be placed in and outside the vineyard to help pinpoint the infestation(s). Vines adjacent to positive traps with 10 or more males should be examined for the presence of VMB females.

\section{Identifying VMBs}

Several different species of mealybugs may infest grapevines. It is important to know which species of mealybug is present because management programs for the various mealybugs differ. VMB cannot be positively identified using a hand lens. If you find mealybugs in your vineyard, collect the largest mealybugs you can find and place them in a jar of alcohol or sealed plastic bag. Take the sample to either your UCCE Farm Advisor or county agricultural commissioner. The phone number and location of these offices can be found in the government pages of the phone book under "County Government." UCCE offices can also be found on the UC Agriculture and Natural Resources Web site 
at http://ucanr.org/ce.cfm. California agricultural commissioners can also be found on the California Department of Food and Agriculture Web site at http://www.cdfa.ca.gov/ exec/cl/countyagmap.htm.

\section{PREVENTING THE SPREAD OF VINE MEALYBUG}

You can help limit the spread of VMBs using the following simple steps.

- Become educated on the VMB by attending local meetings and reading information from your UCCE Farm Advisor or county agricultural commissioner.

- Use pheromone traps to detect or determine the extent of VMB populations in your area.

- Thoroughly clean any and all equipment that has been in an infested area, including sprayers, harvesting bins and boxes, trailers, shovels, hoes, pruning shears, mechanical pruning equipment, etc. If in doubt, clean the equipment.

- Ensure that field crews do not enter uninfested vineyards after working in an area infested with VMBs.

- Rake up and dispose of fallen leaves in infested vineyards as the leaves may harbor VMBs.

- Obtain planting material from sources that trap for VMBs and/or hot water dip dormant grapevines (fig. 12).

- Do not take cuttings from areas that are known to be infested.

- VMBs can survive crushing and de-stemming, so use care when bringing winery waste into your vineyard.

- Make sure your neighboring grape growers are aware of this pest.

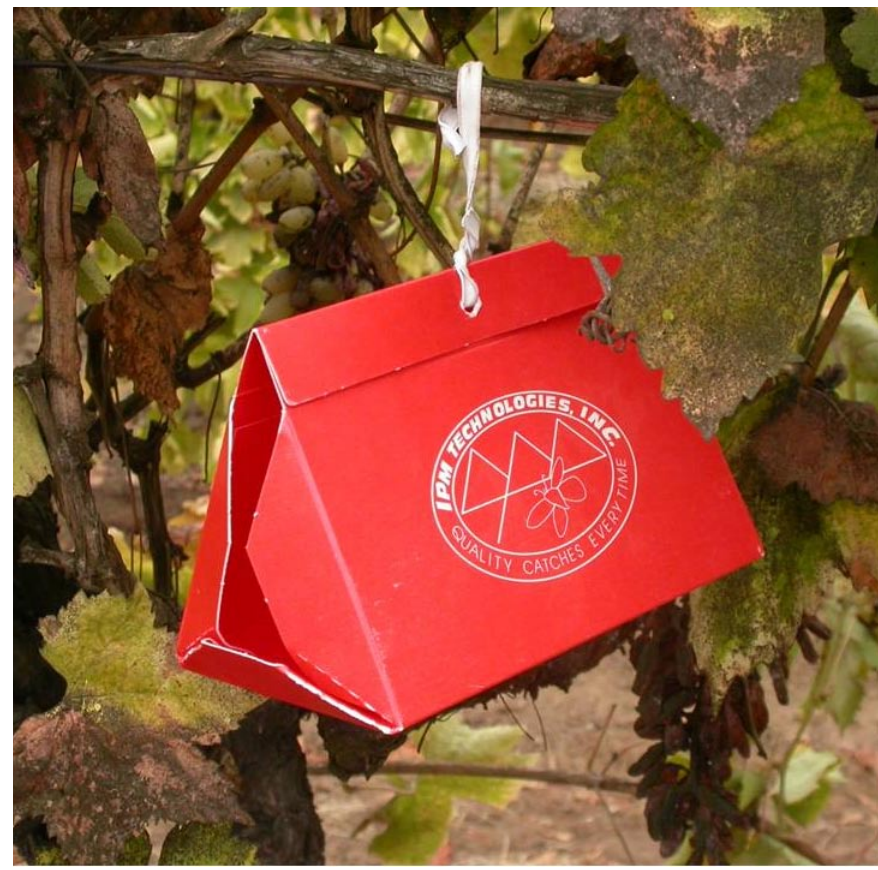

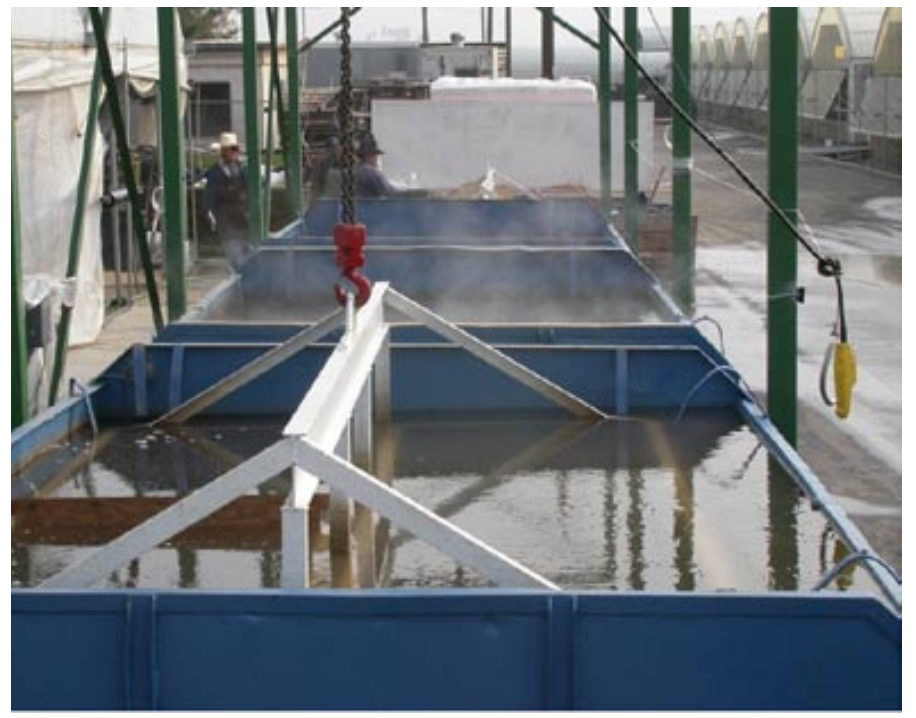

Figure 12. Hot water treatments ensure that dormant nursery vines are free of VMB. Photo by David Haviland.

Figure 11. Pheromone traps hung in the canopy attract and capture male VMBs. Photo by David Haviland. 
Figure 13. Ants tending VMBs to obtain honeydew on which they feed. The ants may protect the VMB from predators and parasites. Photo by Vaughn Walton.
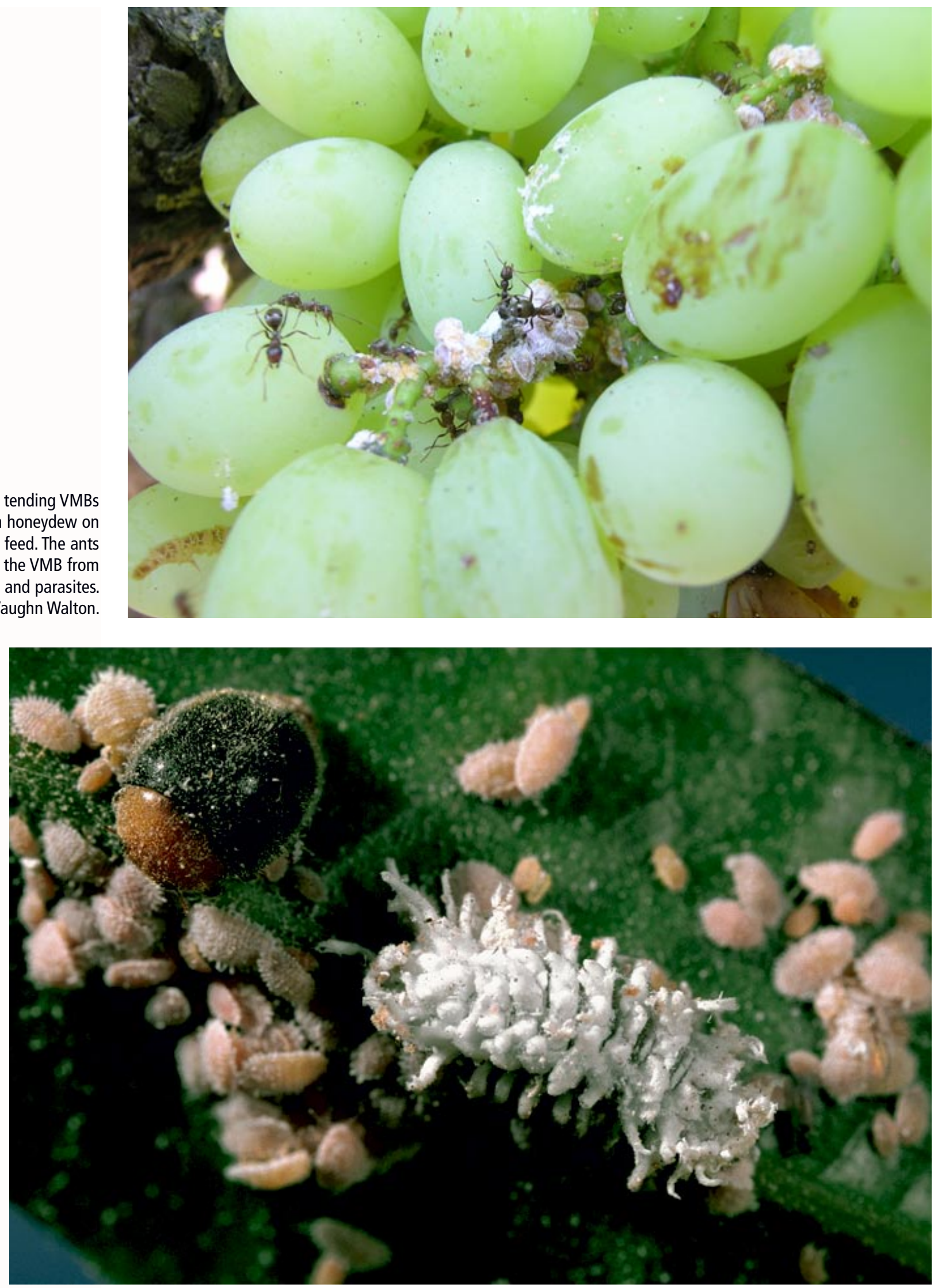

Figure 14. Crytolaemus montrouzieri larva (right) and adult (left) feed on VMBs. Photo by Jack Kelly Clark. 


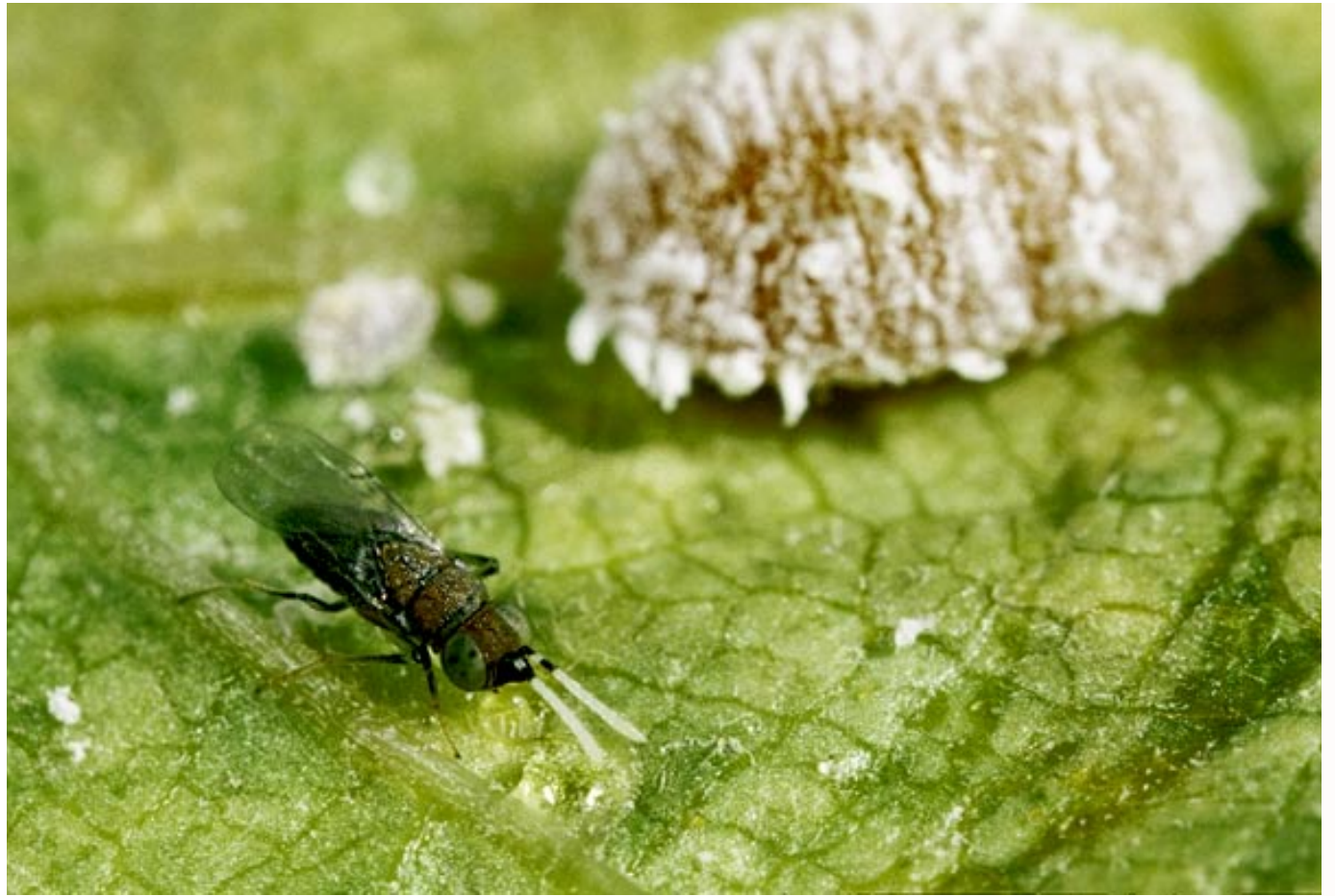

Figure 15. Anagyrus pseudococci female searching for VMB. Photo by Jack Kelly Clark.
MANAGEMENT OF VINE MEALYBUG

Aggressive treatment programs started when VMB infestations are small can reduce their spread and reduce the number of acres that require treatment. Treatments should be aimed at obtaining clean fruit and avoiding having populations in the canopy that may spread due to leaf fall, pruning activities, and harvest activities. Details for the management program can be found in the UC pest management

guidelines, available from either your UCCE Farm Advisor or online at the UC IPM Web site, http://www.ipm.ucdavis.edu/PMG/. The guidelines include current insecticide treatment recommendations.

\section{Ants and VMB}

Some species of ants will tend VMBs and feed on the honeydew produced (fig. 13). The ants may also protect VMBs by keeping parasites and predators away. VMB populations can sometimes be found on the vine by following the ants.

\section{Biological Control}

VMB is attacked by various arthropod predators (fig. 14) and by a small wasp, Anagyrus pseudococci (fig. 15). This wasp was introduced in the 1940s and 1950s against citrus mealybug, a close relative of VMB. Research on other biological control agents is ongoing.

\section{SUMMARY}

- VMB is a small, cryptic insect that can cause severe economic damage in grapes.

- VMB spread can be limited by using proper sanitation and cultural practices.

- Educating yourself about the VMB is one of the best ways to minimize your risk of having VMBs in your vineyard.

- Keep your eyes open for vines that appear abnormal.

- If you think you may have VMBs, please submit a sample to your local UCCE Farm Advisor or county agricultural commissioner's office.

- An aggressive and comprehensive treatment program may avoid large-acreage treatments.

- By working together, we can limit the impact of VMB on the grape industry of California. 


\section{FOR FURTHER INFORMATION}

Additional information about VMB can be obtained from your local UCCE Farm Advisor or in the following sources:

Mealybugs in California Vineyards, ANR Publication 21612, 2002

Mealybugs in California Web site, Kearney Agricultural Center, http://vinemealybug.uckac.edu

University of California IPM Pest Management Guidelines: Grape, available for free downloading at the UC IPM Web site, http://www.ipm.ucdavis.edu/PMG/

To order or obtain printed publications and other products, visit the ANR Communication Services online catalog at http://anrcatalog.ucdavis.edu. You can also place orders by mail, phone, or FAX, or request a printed catalog of our products from:

University of California

Agriculture and Natural Resources

Communication Services

6701 San Pablo Avenue, 2nd Floor

Oakland, California 94608-1239

Telephone: (800) 994-8849 or (510) 642-2431

FAX: (510) 643-5470

E-mail inquiries: danrcs@ucdavis.edu

An electronic version of this publication is available on the ANR Communication Services Web site at http://anrcatalog.ucdavis.edu.

The authors wish to thank the following contributors: Nick Frey (Sonoma County Grape Growers Association), John Duarte (Duarte Nursery, Inc.), and Dana Merrill (Mesa Vineyard Management, Inc.).

Production of this publication has been supported by grant from the California Department of Food and Agriculture, Pest Exclusion Branch, Nursery, Seed, and Cotton Services Program.

Publication 8152

(C) 2005 by the Regents of the University of California, Division of Agriculture and Natural Resources. All rights reserved.

The University of California prohibits discrimination or harassment of any person on the basis of race, color, national origin, religion, sex, gender identity, pregnancy (including childbirth, and medical conditions related to pregnancy or childbirth), physical or mental disability, medical condition (cancer-related or genetic characteristics), ancestry, marital status, age, sexual orientation, citizenship, or status as a covered veteran (covered veterans are special disabled veterans, recently separated veterans, Vietnam era veterans, or any other veterans who served on active duty during a war or in a campaign or expedition for which a campaign badge has been authorized) in any of its programs or activities. University policy is intended to be consistent with the provisions of applicable State and Federal laws.

Inquiries regarding the University's nondiscrimination policies may be directed to the Affirmative Action/Staff Personnel Services Director, University of California, Agriculture and Natural Resources, 300 Lakeside Drive, 6th Floor, Oakland, CA 94612-3550 (510) 987-0096. For a free catalog of other publications, call (800) 994-8849. For help downloading this publication, call (530) 754-5112.

pr-1/05-SB/CR

ISBN 978-1-60107-322-8

This publication has been anonymously peer reviewed for technical accuracy by University of California scientists and other qualified professionals. This review process was managed by the ANR Associate Editor for Pest Management. 